\title{
Influence of the Socio-Cultural Environment and External Factors in Following Plant-Based Diets
}

\author{
Ujué Fresán ${ }^{1,2,3, * \mathbb{C}}$, Sofie Errendal ${ }^{4,5}$ and Winston J. Craig ${ }^{6}$ \\ CIBER-Epidemiología y Salud Pública, Instituto de Salud Carlos III, 28029 Madrid, Spain \\ Instituto de Salud Pública y Laboral de Navarra, 31003 Navarra, Spain \\ IdiSNA, Instituto de Investigación Sanitaria de Navarra, 31008 Pamplona, Spain \\ 4 Global Health and Nutrition, University College Copenhagen, 2200 Copenhagen, Denmark; \\ errendal@live.dk \\ 5 Social Sciences Faculty, Lund University, 22020 Lund, Sweden \\ 6 Center for Nutrition, Healthy Lifestyles, and Disease Prevention, School of Public Health, \\ Loma Linda University, Loma Linda, CA 92354, USA; wcraig@llu.edu \\ * Correspondence: ujuefresan@gmail.com
}

Received: 9 September 2020; Accepted: 27 October 2020; Published: 31 October 2020

\begin{abstract}
A general transition to plant-based diets is recommended for improved human and planetary health. The information about why people opt for plant-based diets can be used to profile future health promotion initiatives. We studied the reasons that encouraged the adoption and maintenance of plant-based diets and the influence of the socio-cultural environment and other external factors. Through the use of a specifically designed questionnaire, we evaluated two different populations. Interpreting data from 229 participants, we observed the relevance of adapting strategies to motivate people to embrace plant-based diets according to their socio-cultural environment. External factors facilitating access to plant-based products appeared to be essential in both populations.
\end{abstract}

Keywords: plant-based diet; diet motivation; vegan; vegetarian; food price; plant-based food availability

\section{Introduction}

No longer is it enough to only focus on health effects when assessing dietary patterns. In 2010, the Food and Agriculture Organization of the United Nations (FAO) indicated that other aspects of diets, apart from the nutritional value, should be taken into account to achieve a more holistic assessment of the diet. FAO coined the term sustainable diets, defining these as "those diets with low environmental impacts which contribute to food and nutrition security and to a healthy life for present and future generations. Sustainable diets are protective and respectful of biodiversity and ecosystems, culturally acceptable, accessible, economically fair and affordable; nutritionally adequate, safe and healthy; while optimizing natural and human resources" [1].

Since then, increasing attention has been given to sustainable diets [2-4]. An example of such sustainable diets is plant-based diets, which focus on foods primarily from plants and limit or avoid animal-based foods. These diets have been proposed as more sustainable alternatives to the current animal-based, western diets [5]. Plant-based diets comprise specific types of dietary patterns such as flexitarian (includes eggs, dairy foods, and occasionally meat, poultry, fish, and seafood), pescatarian (includes eggs, dairy foods, fish, and seafood, but no meat or poultry), lacto-ovo-vegetarian (includes eggs and dairy foods, but no meat, poultry, fish, or seafood), and vegan (includes no animal foods) [6]. A transition to any of these diets has the potential to achieve human and planetary health benefits [7-14].

The proportion of people who follow plant-based diets varies among the various regions of the world. While $19 \%$ of people residing in the Asia Pacific region self-declare as vegetarians, just $5 \%$ 
and 6\% of Europeans and North Americans, respectively, do [15]. People who actually follow plant-based dietary patterns may have adopted them for one or more reasons [16,17]. Reasons for continuing plant-based diets could be different from the ones that encouraged their adoption [18-21]. Personal concerns about the health effects of current dietary patterns, animal welfare, and environmental sustainability have been pointed out as motivations for people to follow plant-based diets $[16,18,20]$. However, various barriers exist, such as a general lack of knowledge about plant-based diets and the palatability of meat $[18,22,23]$. In addition, there is the challenge of changing one's eating habits $[18,22,23]$. Personal identity, including the dietarian identity, could be influenced by the socio-cultural environment [22]. The perception of meat consumption in the community due to cultural traditions or religious beliefs can influence dietary decisions $[18,22]$. Support from family and friends is also a guiding factor [20]. Additionally, societal and global trends and the influence of the media may also play a central role in embracing plant-based diets [24,25]. Beyond this, other external factors could be decisive; food environment (i.e., availability of plant-based options in usual grocery stores and restaurants, and the way they are displayed or promoted) and the food price are also key elements for the dietary transition [26-28].

The current research's aim was to study reasons that initially encouraged the adoption of plant-based diets, and their maintenance over time, amongst those who actually follow plant-based diets in two different socio-cultural backgrounds. In addition, the availability of plant-based foods and other external factors that could influence dietary behavior were also evaluated. Such an analysis may expand our understanding of food choice behavior and assist nutrition educators and policymakers in developing effective strategies to promote sustainable diets.

\section{Materials and Methods}

Supplementary Table S1 shows a summary of the methodology followed in the current study.

\subsection{Study Population and Settings}

The inclusion criteria were related to dietary and location aspects. On one hand, participants had to follow plant-based diets. They self-declared their dietary preference as flexitarian, pescatarian, vegetarian, or vegan. Regarding the location, participants were recruited from two different cities, an American (Loma Linda (LL), California) and a European (Copenhagen (CPH), Denmark) city. LL is a small city of around 24,000 inhabitants [29]. In order to collect enough responses, LL participants had to live in LL or in close proximity cities (i.e., Redlands, San Bernardino, and Riverside). CPH participants had to live in the city of $\mathrm{CPH}$, including the municipality of Frederiksberg. No further expansion was need as the population of CPH (around 793,000 inhabitants) provided a sufficient pool of participants [30]. There was no restriction in terms of gender, age, race, or socioeconomic status.

These two locations represented two different socio-cultural environments. LL is unique because it is one of the five Blue Zones, cities of the world characterized by people living a healthy lifestyle and having a long life expectancy [31]. In addition, LL is predominantly a Seventh-Day Adventist (SDA) community. The SDA church promotes the consumption of plant-based diets but also allows the consumption of animal-based products (such as egg and dairy). Pork, shellfish, and other specific animal-derived products are strongly discouraged [32,33]. On the other hand, $\mathrm{CPH}$ won the European Green Cities award for its great commitment to green growth and sustainability initiatives [34]. It could be expected that participants from LL followed plant-based diets because of health and religious reasons, while people from $\mathrm{CPH}$ embraced plant-based diets because of environmental reasons. 


\subsection{Questionnaire}

To collect data, we designed a self-administered, web-based, and closed questionnaire. Questions were multiple-choice, single answer. In total, it contained 22 questions, divided into four categories: demographics; personal diet and motivation; society and culture; and external factors. Two versions were developed: English, for LL participants, and Danish, translated for $\mathrm{CPH}$ respondents.

Our questionnaire was based on Stoll-Kleemann and Smith's model established according to a systematic review of the most relevant factors influencing meat-eating behavior [26]. The questionnaire utilized the main categories (personal/internal, socio-cultural, and external factors) in sections and sub-categories in the individual questions. The socio-demographic characteristics (Table 1 questions in our study) were designed to specify the socio-demographics of the sample and included gender, age, religion, and level of education. Personal diet and motivation of participants (Table 2) were guided by the sections in Stoll-Kleemann and Smith of "Knowledge \& skills", "Emotions \& Cognitive Dissonance", "Values \& Attitudes", "Habits \& Tastes", and "Perceived behavior control". The socio-cultural environment questions (Table 3) were constructed based on the section of the same name in Stoll-Kleemann and Smith's paper. It includes: "Culture \& religion", "Social norms, roles and relationships", and "Social identity and lifestyles". The availability of plant-based food (Table 4) is based on the external factors section, which includes "Political \& Economic factors" and "Food environment (infrastructure, access, products)".

Table 1. Socio-demographic characteristics of participants by location.

\begin{tabular}{|c|c|c|}
\hline & LOMA LINDA & COPENHAGEN \\
\hline Frequency (n) & 43 & 186 \\
\hline \multicolumn{3}{|c|}{ 1. Gender } \\
\hline Women & 76.7 & 87.1 \\
\hline Men & 23.3 & 11.8 \\
\hline Preferred not to disclose & 0.0 & 1.1 \\
\hline \multicolumn{3}{|c|}{ 2. Age } \\
\hline 19 years or younger & 0.0 & 9.1 \\
\hline 20-29 years & 53.5 & 54.8 \\
\hline 30-39 years & 11.6 & 17.7 \\
\hline $40-49$ years & 11.6 & 13.4 \\
\hline 50-59 years & 16.3 & 3.2 \\
\hline $60-69$ years & 2.3 & 1.1 \\
\hline 70 years or older & 4.7 & 0.5 \\
\hline \multicolumn{3}{|c|}{ 3. Religion } \\
\hline Christian & 58.1 & 13.4 \\
\hline Seventh-Day Adventist & 55.8 & 0.0 \\
\hline Other protestant & 2.3 & 13.4 \\
\hline No religion & 9.3 & 70.4 \\
\hline Others & 32.6 & 16.2 \\
\hline \multicolumn{3}{|c|}{ 4. Level of Education } \\
\hline High school graduate & 0.0 & 4.8 \\
\hline College degree & 9.3 & 25.3 \\
\hline Undergraduate/Bachelor's degree & 39.5 & 30.6 \\
\hline Graduate/Master's degree & 34.9 & 19.9 \\
\hline Doctoral Degree & 11.6 & 2.7 \\
\hline Professional degree & 4.7 & 10.8 \\
\hline Other & 0.0 & 5.9 \\
\hline
\end{tabular}

Data reported as \%. 
Table 2. Personal diet and motivation of participants by location.

\begin{tabular}{|c|c|c|}
\hline & LOMA LINDA & COPENHAGEN \\
\hline Frequency (n) & 43 & 186 \\
\hline \multicolumn{3}{|c|}{ 1. Which diet do you follow on a regular basis? } \\
\hline Flexitarian (eats meat, poultry, or fish occasionally) & 39.5 & 21.0 \\
\hline Pescatarian (eats fish and dairy and/or eggs, but not meat) & 16.3 & 6.5 \\
\hline Lacto-ovo-vegetarian (eats dairy or eggs or both, but not meat nor fish) & 25.6 & 24.7 \\
\hline Vegan (eats only plant foods) & 18.6 & 47.8 \\
\hline \multicolumn{3}{|l|}{ 2. How long have you followed this diet? } \\
\hline Less than 1 year & 7.0 & 21.0 \\
\hline $1-5$ years & 23.3 & 51.1 \\
\hline $5-10$ years & 9.3 & 15.6 \\
\hline $10-15$ years & 16.3 & 4.8 \\
\hline $15-20$ years & 9.3 & 1.1 \\
\hline 20 years or more & 34.9 & 6.5 \\
\hline \multicolumn{3}{|c|}{ 3. Which of the following areas motivated you to start your diet? } \\
\hline Health & 53.5 & 22.6 \\
\hline Weight loss & 0.0 & 2.2 \\
\hline Environment/Climate change & 0.0 & 22.0 \\
\hline Animal welfare & 7.0 & 39.8 \\
\hline Social norm (if friends and family eat this way) & 16.3 & 1.1 \\
\hline Religious/Spiritual belief & 11.6 & 0.5 \\
\hline Taste & 0.0 & 3.8 \\
\hline Saving money & 0.0 & 0.5 \\
\hline Political reasons & 0.0 & 1.6 \\
\hline Convenience & 0.0 & 0.0 \\
\hline Diet trend & 0.0 & 0.5 \\
\hline Other & 11.6 & 5.4 \\
\hline \multicolumn{3}{|c|}{ 4. Which of the following areas motivates you to continue this diet? } \\
\hline Health & 69.8 & 22.0 \\
\hline Weight loss & 0.0 & 1.1 \\
\hline Environment/Climate change & 2.3 & 28.5 \\
\hline Animal welfare & 4.7 & 40.9 \\
\hline Social norm (if friends and family eat this way) & 2.3 & 0.5 \\
\hline Religious/Spiritual belief & 7.0 & 0.0 \\
\hline Taste & 0.0 & 3.2 \\
\hline Saving money & 0.0 & 0.0 \\
\hline Political reasons & 0.0 & 0.0 \\
\hline Habit & 7.0 & 1.6 \\
\hline Convenience & 4.7 & 0.0 \\
\hline Diet trend & 0.0 & 0.0 \\
\hline Other & 2.2 & 2.2 \\
\hline \multicolumn{3}{|c|}{ 5. Would you eat more plant-based than you do now ${ }^{1}$, if } \\
\hline It was cheaper. & 11.4 & 13.4 \\
\hline It tasted better. & 5.7 & 5.2 \\
\hline $\begin{array}{l}\text { You could get the plant-based alternative for those food items/dishes you love } \\
\text { (e.g., burger, meatballs, chicken tikka masala, cheese, yogurt, butter, etc.). }\end{array}$ & 8.6 & 1.0 \\
\hline It was more convenient/easier to get plant-based food. & 11.4 & 10.3 \\
\hline It was less time consuming. & 8.6 & 9.3 \\
\hline There would be a greater selection of plant-based items in your supermarkets. & 2.9 & 7.2 \\
\hline More restaurants and cafes offered plant-based meals. & 17.1 & 7.2 \\
\hline More of my friends and family followed the same diet. & 8.6 & 15.5 \\
\hline The person cooking in my home, would cook plant-based meals. & 2.9 & 5.2 \\
\hline None, I am already eating a satisfactory diet. & 11.4 & 23.7 \\
\hline Other & 11.4 & 2.0 \\
\hline
\end{tabular}


Table 3. Socio-cultural environment of participants by location.

\begin{tabular}{|c|c|c|}
\hline & LOMA LINDA & COPENHAGEN \\
\hline Frequency (n) & 43 & 186 \\
\hline \multicolumn{3}{|c|}{ 1. Do you follow the same diet as the majority of your family (parents, partner, children)? } \\
\hline Yes & 48.8 & 21.0 \\
\hline No & 51.2 & 79.0 \\
\hline \multicolumn{3}{|c|}{ 2. If no, which diet do the majority of your family follow? } \\
\hline Omnivore (eats meat and plant food) & 59.1 & 76.2 \\
\hline Flexitarian (eats meat, poultry, or fish occasionally) & 4.5 & 21.1 \\
\hline Pescatarian (eats fish and dairy and/or eggs, but not meat) & 9.1 & 0.0 \\
\hline Lacto-ovo-vegetarian (eats dairy or eggs or both, but not meat nor fish) & 18.2 & 1.4 \\
\hline Vegan (eats only plant foods) & 4.5 & 0.0 \\
\hline Other & 4.6 & 1.3 \\
\hline \multicolumn{3}{|c|}{ 3. Do you follow the same diet as the majority of your friends? } \\
\hline Yes & 27.9 & 14.5 \\
\hline No & 72.1 & 85.5 \\
\hline \multicolumn{3}{|c|}{ 4. If no, which diet do the majority of your friends follow? } \\
\hline Omnivore (eats meat and plant food) & 71.0 & 79.2 \\
\hline Flexitarian (eats meat, poultry, or fish occasionally) & 12.9 & 17.6 \\
\hline Pescatarian (eats fish and dairy and/or eggs, but not meat) & 0.0 & 0.0 \\
\hline Lacto-ovo-vegetarian (eats dairy or eggs or both, but not meat nor fish) & 9.7 & 1.3 \\
\hline Vegan (eats only plant foods) & 3.2 & 0.0 \\
\hline Other & 3.2 & 1.9 \\
\hline \multicolumn{3}{|c|}{ 5. Do you ever compromise your diet because of social pressure? } \\
\hline Yes, very often. & 2.3 & 13.4 \\
\hline Sometimes. & 41.9 & 27.4 \\
\hline No, rarely. & 55.8 & 59.1 \\
\hline \multicolumn{3}{|c|}{ 6. Is eating a more plant-based diet associated with the religion/spiritual beliefs in your city? } \\
\hline Yes. & 65.1 & 0.0 \\
\hline No. & 27.9 & 86.6 \\
\hline I do not know. & 7.0 & 13.4 \\
\hline
\end{tabular}

7. According to you, which of the following statements do you think suits best with how lacto-ovo-vegetarian diet is perceived in your city?

A lifestyle which promotes health.

$67.4 \quad 8.1$

A lifestyle for women.

$0.0 \quad 3.8$

A lifestyle for weight loss.

$2.3 \quad 0.5$

A lifestyle for very health conscious individuals. $\quad 2.3 \quad 11.3$

$\begin{array}{lll}\text { A lifestyle for lower income families. } & 0.0 & 0.0\end{array}$

A lifestyle for higher income families. $\quad 0.0 \quad 0.5$

$\begin{array}{lll}\text { A lifestyle for certain religious/spiritual beliefs. } & 23.3 & 0.5\end{array}$

A lifestyle for individuals who have strong beliefs in animal rights. $\quad 2.3 \quad 27.4$

$\begin{array}{lll}\text { A lifestyle for addressing and reducing climate change. } & 2.3 & 31.2\end{array}$

I do not know.

$2.4 \quad 16.7$

8. According to you, which of the following statements do you think suits best with how vegan diet is perceived in your city?

$\begin{array}{lcc}\text { A lifestyle which promotes health. } & 25.6 & 2.2 \\ \text { A lifestyle for women. } & 2.3 & 2.2 \\ \text { A lifestyle for weight loss. } & 0.0 & 0.0 \\ \text { A lifestyle for very health conscious individuals. } & 30.2 & 8.1 \\ \text { A lifestyle for lower income families. } & 0.0 & 0.0 \\ \text { A lifestyle for higher income families. } & 0.0 & 1.1 \\ \text { A lifestyle for certain religious/spiritual beliefs. } & 16.3 & 1.6 \\ \text { A lifestyle for individuals who have strong beliefs in animal rights. } & 18.6 & 53.2 \\ \text { A lifestyle for addressing and reducing climate change. } & 0.0 & 15.6 \\ \text { I do not know. } & 7.0 & 16.0\end{array}$


Table 4. Availability of plant-based foods in both locations.

\begin{tabular}{|c|c|c|}
\hline & LOMA LINDA & COPENHAGEN \\
\hline Frequency (n) & 43 & 186 \\
\hline \multicolumn{3}{|c|}{$\begin{array}{l}\text { 1. Do you find it easy to shop basic food alternatives suitable for lacto-ovo-vegetarians and/or vegans in } \\
\text { your area (such as legumes, tofu, tempeh, vegetable milk, etc.)? }\end{array}$} \\
\hline $\begin{array}{l}\text { Yes, it is no problem to find basic plant-based items in the } \\
\text { supermarkets here. }\end{array}$ & 76.7 & 46.8 \\
\hline $\begin{array}{l}\text { Most of the time, yes, although I can't always get what I need } \\
\text { from one store. }\end{array}$ & 23.3 & 48.9 \\
\hline $\begin{array}{l}\text { No, I find it difficult to find basic plant-based items in } \\
\text { supermarkets here. }\end{array}$ & 0.0 & 4.3 \\
\hline \multicolumn{3}{|c|}{$\begin{array}{l}\text { 2. Do you find it easy to shop ready-to-eat items suitable for lacto-ovo-vegetarians and/or vegans in your } \\
\text { area? }\end{array}$} \\
\hline $\begin{array}{l}\text { Yes, it is no problem to find lacto-ovo-vegetarian meals in the } \\
\text { supermarkets here. }\end{array}$ & 41.9 & 12.4 \\
\hline $\begin{array}{l}\text { Yes, it is no problem to find both lacto-ovo-vegetarian and } \\
\text { vegan meals in the supermarkets here. }\end{array}$ & 18.6 & 27.4 \\
\hline Sometimes. & 25.6 & 39.2 \\
\hline No, I find it difficult to find either. & 7.0 & 12.4 \\
\hline I haven't looked for it. & 6.9 & 8.6 \\
\hline
\end{tabular}

3. Do you think that foods suitable for lacto-ovo-vegetarians or vegans are too expensive compared to animal-based foods?

\begin{tabular}{lcc}
\hline Yes, lacto-ovo-vegetarian and/or vegan options are more & 58.1 & 81.2 \\
expensive than animal-based ones. & 20.9 & 11.8 \\
$\begin{array}{l}\text { I think they are about the same. } \\
\text { No, lacto-ovo-vegetarian and/or vegan options are cheaper }\end{array}$ & 16.3 & 2.2 \\
than animal-based ones. & 4.7 & 4.8 \\
\hline
\end{tabular}

4. Is there a lack of lacto-ovo-vegetarian or vegan meal options at your work, school or the place you spend the most of your day?

\begin{tabular}{lcc}
\hline Yes, both meal options are missing. & 2.3 & 22.0 \\
They have lacto-ovo-vegetarian meals, but not vegan & 20.9 & 26.3 \\
meal options. & 9.3 & 12.9 \\
Sometimes the options are available. & 7.0 & 6.5 \\
No, the options are available, but the dishes are not very good. & 55.8 & 14.5 \\
No, both meal options are available. & 4.7 & 17.8 \\
Not applicable
\end{tabular}

5. Is there a lack of lacto-ovo-vegetarian or vegan meals when you eat out?

\begin{tabular}{lcc}
\hline Yes, both meal options are missing. & 4.7 & 10.8 \\
Most places have lacto-ovo-vegetarian meals, but not vegan & 58.1 & 60.2 \\
meal options. & 9.3 & 14.5 \\
Sometimes the options are available. & 9.3 & 4.8 \\
No, the options are available, but the dishes are not very good. & 16.3 & 7.0 \\
No, both meal options are available. & 2.3 & 2.7 \\
Other
\end{tabular}

Data reported as $\%$.

A pilot test was carried out on two persons in each location (four people in total) to ensure comprehension and content validity. A list with all the questions was given to them, and they explained the way they understood each question. Afterwards, pilot participants answered the questions. Responses were then decoded to ensure their alignment with the questionnaire's answer options. Furthermore, respondents were asked to comment on the content of the questionnaire, and whether 
they thought it omitted any perspective in relation to the research question. The questionnaire was revised and edited according to the feedback received.

\subsection{Data Collection}

We designed a poster with a link and a Quick Response (QR) code to the questionnaire. It also included a brief explanation of the objective of the study, inclusion criteria, and contact information. We set a minimum of eight respondents per diet category (i.e., flexitarian, pescatarian, vegetarian, and vegan) and at least 40 participants in total.

Data collection in LL was conducted from July to September 2018. In CPH, data were collected during two weeks in October of the same year. In LL, the poster was posted on some public Facebook groups and distributed in local supermarkets and cafés. Additionally, flyers were distributed directly to the university campus community and an advertisement was posted in an online newspaper. In $\mathrm{CPH}$, seven Facebook groups were contacted following the same procedure as in LL, uploading the poster at those sites. No paper posters or flyers were distributed in $\mathrm{CPH}$, as enough participants were recruited from the Facebook postings.

Voluntary completion of the questionnaire by participants implied informed consent, as participants received information about its anonymity and details about the research propose.

\subsection{Statistical Analyses}

Descriptive statistics (frequencies and percentages) were used to define the socio-demographic characteristics of the respondents in both locations, their personal diet and motivating factors, their socio-cultural environment, and the availability of plant-based products in both locations. No comparison between groups or the two populations was performed.

\section{Results}

\subsection{Socio-Demographic Characteristics}

Our sample included a total of 229 participants, 43 from LL and 186 from CPH. The main characteristics according to demographics are shown in Table 1 . In both cases, more than three-quarters of the participants were women, and more than half of the participants were aged between 20 and 29 years. Participants from both places reported a high level of education. While more than $50 \%$ of the LL's participants followed the SDA religion, 70\% of the interviewed people in CPH declared not following any religion.

\subsection{Personal Diet and Motivations}

According to the participants' personal diets (Table 2), most people in LL followed flexitarian $(39.5 \%)$ or pescatarian $(25.6 \%)$ diets, while nearly $50 \%$ of the CPH participants self-declared as vegans. One-third of the LL sample had followed their diet for 20 years or more, while over $50 \%$ of the CPH sample had followed a plant-based diet for 1 to 5 years. In LL, more than half of the participants reported health as the main motivation to start following a plant-based diet. Other relevant reasons were the social norm and religion. In $\mathrm{CPH}$, around $40 \%$ mentioned concerns about animal welfare as a motivating factor, while health and environmental/climate change issues each accounted for around $22 \%$ of the responses. The major reason for maintaining the diet in LL was health $(69.8 \%)$, while in $\mathrm{CPH}$ animal welfare was the main motivation to continue the diet $(40.9 \%)$, followed by the environmental/climate change response (28.5\%).

Comparing non-vegan participants in both locations, $23.7 \%$ of the respondents from $\mathrm{CPH}$ considered themselves as already consuming enough plant-based products, while just $11.4 \%$ selected this option in LL. Most of the respondents in LL said that they would increase the consumption of plant-based foods if the availability was higher (specifically in restaurants and cafés) and if plant-based options were cheaper. On the other hand, having friends and family who follow the same dietary 
pattern, a lower price, and greater convenience of plant-based foods could increase the consumption of plant-based foods among participants from CPH (Table 2).

\subsection{Socio-Cultural Environment}

As shown in Table 3, 51.2\% and 72.1\% of LL participants followed different dietary patterns than their family and friends, respectively. In the case of $\mathrm{CPH}$, these responses were $79.0 \%$ and $85.5 \%$, respectively. In both populations, the omnivorous diet was the most commonly reported diet for relatives and friends. More than half of the participants of both places affirmed that they never or rarely compromised their diet because of social pressure. More people reported compromising their diet "very often" in CPH.

In general, plant-based diets were considered by most of the LL participants to be associated with religion/spiritual beliefs (65.1\%) while the opposite (non-religious association) was reported by $86.6 \%$ $\mathrm{CPH}$ participants (Table 3). In LL, two-thirds of the participants reported that the lacto-ovo-vegetarian diet is associated in their city with a lifestyle which promotes health. The rest of the respondents mainly indicated that it is related to religion. In $\mathrm{CPH}$, more people thought that is considered a lifestyle for those individuals who have strong animal rights beliefs, or as a way to mitigate climate change. In LL, the vegan diet was associated with health, but also with religion and animal rights, while a stronger association with the latter was reported in $\mathrm{CPH}$.

\subsection{Availability of Plant-Based Foods}

In neither of the two populations does it appear to be very difficult to shop for animal food alternatives or ready-to-eat products suitable for lacto-ovo-vegetarians and/or vegans. The availability of these types of products in supermarkets, nevertheless, seemed higher in LL. The majority of both populations considered that plant-based foods are more expensive than animal-sourced products, with special emphasis among the participants from CPH. While 55.8\% of LL participants reported that both lacto-ovo-vegetarian and vegan options are available at the place where they work or study, $48.3 \%$ of the $\mathrm{CPH}^{\prime}$ s participants indicated that both or at least vegan options are not available at their work or study place. More than half of the participants in both locations reported that the majority of restaurants offer lacto-ovo-vegetarian meals and, to a lesser degree, vegan options (Table 4).

\section{Discussion}

The findings generated by this study highlight the influence of the socio-cultural background and external factors on people's dietary decisions. Our study supports previous reports describing how personal dietary choices are influenced by the environment $[20,26]$.

For the samples that we surveyed, we observed that, in both populations, the respondents were mainly young women with a high level of education, confirming previous studies associating plant-based diets with the female sex, young age, and a high level of education $[19,20,22,26]$. As expected, the respondents from both locations greatly differed in one cultural-related characteristic: religion. While more than half of the LL participants were Christians, specifically Seventh-Day Adventist, $70 \%$ of the $\mathrm{CPH}$ respondents declared that they did not follow any specific religion. In LL, a reasonable proportion of participants mentioned religion as the main reason for starting and continuing to follow plant-based diets. Furthermore, participants themselves mentioned that plant-based diets in general, and both lacto-ovo-vegetarian and vegan diets in particular, are associated with religion by the general population in their place. However, religion was not mentioned as a motivational factor among $\mathrm{CPH}$ participants, and these dietary patterns were not considered to be related to religion.

Health and animal welfare have been constantly described in the literature as the main reasons for adopting plant-based diets $[16,18-20,22]$. We observed that health was reported by more than half of the respondents as the main motivation for their dietary choice in LL. CPH participants also mentioned the relevance of health, but not to the same extent as LL participants did. Animal welfare, followed by environmental sustainability/climate change concerns, were the main reasons among $\mathrm{CPH}$ 
participants. Vegan dieters reported more frequently animal welfare as their main diet motivation as compared to people whose plant-based diet still includes some animal-derived foods (i.e., flexitarian, pescatarian, and vegetarian diets) $[16,20,22]$. In LL, more than $65 \%$ self-declared as flexitarians or pescatarians-in other words, consuming, at least occasionally, flesh-based products. On the other hand, nearly $50 \%$ in $\mathrm{CPH}$ were vegan. This is in accordance with the fact that LL participants pointed out health as their main motivational reason, while CPH selected animal welfare. In addition, our findings are consistent with LL being an SDA community and one of the Blue Zones, and CPH being awarded for the implementation of green measures. California, on the other hand, has been a leader in environmental advocacy for many years, promoting the sustainability of plant-based diets [35-37]. Nevertheless, LL respondents rarely mentioned environment/climate change reasons as their major motivation. This could be explained because our questionnaire only allows one answer for each question. According to the literature, a mix of motives could be similarly important $[16,17]$. Future research using open-ended or multi-selection answer questionnaires would help to clarify this issue.

As reported in the literature, the motive for continuing plant-based diets could be different from the reason that motivated their adoption [18-21]. In LL, the number of people who indicated health as a main factor to start their plant-based diet was $53.5 \%$, while $69.8 \%$ selected it as their motivation to continue such a diet. In CPH, $22 \%$ of respondents indicated the environment/climate change as their major reason for adopting plant-based diets, and $28.5 \%$ selected it as their main reason to maintain the diet. This indicates that health and environmental benefits, respectively, were important issues to motivate people to continue consuming plant-based diets.

Reports have mentioned the relevance of social networks in influencing the habits of those consuming plant-based diets [21,22]. People who follow plant-based diets tend to be involved in groups that explicitly support these dietary patterns $[18,38,39]$. In both populations, we observed that social networks could be critical in maintaining common dietary practices of plant-based consumers. They sometimes, or even frequently in the case of $\mathrm{CPH}$, compromised their diet because of social pressure. Accordingly, they reported that they would consume more plant-based products if peers would follow the same diet. The majority of the participants from both locations reported that their friends and family regularly followed a type of diet different from theirs, the most frequent being the omnivorous diet. More than half of the sample from $\mathrm{CPH}$ followed a vegan diet while a high proportion of the participants from LL were flexitarians or pescatarians. This fact may enhance the social pressure that $\mathrm{CPH}$ participants experienced; thus, the diet was more frequently compromised. In addition, $\mathrm{LL}$, but not $\mathrm{CPH}$, is a very religious community, in which a plant-based diet is seen as central to a religious life. Thus, strong religious beliefs could be another factor that could explain why LL participants did not compromise their diet as frequently as participants from $\mathrm{CPH}$. It should be recognized, however, that one's individual personality often determines the degree to which one may compromise their diet.

External factors could also influence one to embrace specific dietary patterns. It has been reported that an adequate infrastructure supporting plant-based diets is essential [26]. Furthermore, it could be a means to help reduce meat consumption among omnivores, since the increase in the availability of plant-based food products leads to increased consumer usage [28]. Indeed, the World Health Organization has stated that by providing supportive environments at several levels, diet change is more likely to be facilitated and maintained [40]. In our study, basic and ready-to-eat products seem to be accessible in stores and at restaurants in both LL and CPH, at least for the lacto-ovo-vegetarian options. In spite of the presence of these options, their availability still seems insufficient. Certainly, participants suggested their willingness to eat more plant-based products if supermarkets and restaurants would offer a greater selection of plant-based choices. Furthermore, participants in our study considered plant-based alternatives to be more expensive than meat-based products. Price definitely influences people's dietary choices [26]. It was noted that nobody adopted plant-based diets due to cost savings, signaling that products may not be cheap enough to be a major factor 
causing dietary change. However, it should be mentioned that the availability in supermarkets and the affordability of plant-based foods would depend on the type of product. Foods such as legumes and cereals are widely available and are much less expensive than meat. On the other hand, meat analogs, such as veggie burgers or hot dogs, and plant-based milks would increase considerably the basket price. A general transition to plant-based diets goes beyond individual choice and requires support from government policies, health professionals, and the food industry. Governments may have to rethink their food subsidies to facilitate greater availability and accessibility to plant-based options [27]. In addition, restaurants must offer a greater selection of plant-based options in order to support the dietary needs of those wishing to adhere to plant-based diets.

Our study has some limitations. The questionnaire has not been previously validated, and, besides the fact that it had been previously tested in both locations, only two subjects in each site participated in those pilot studies. However, it was based on Stoll-Kleemann and Smith's model, established according to a systematic review of the most relevant factors influencing meat-eating behavior [26]. It was clearly stated as inclusion criteria that participants should follow a plant-based dietary pattern and live in LL or close by, or in CPH. Participants self-declared their usual dietary pattern; its accuracy was not corroborated by a dietary questionnaire. In addition, we cannot rule out that participants ignored this point and lived in other places. Some more socio-demographic information could have been collected, such as race or socio-economic level. The recruitment method used to collect participants was different in LL and $\mathrm{CPH}$; in $\mathrm{CPH}$, it was exclusively done through Facebook groups, while in LL, additional recruitment was done to achieve a greater number of participants. Even then, the sample size was still relatively small, especially in LL. The Facebook groups targeted in CPH were focused on plant-based diets; the lack of this type of specific group in LL led us to select general Facebook groups in that location. This could be the reason for the higher participation in CPH. In addition, the questionnaire was web-based, and people with no internet access or without enough computer skills were not able to complete it. Altogether, a selection bias could not be ruled out. Nevertheless, our questionnaire has been shown to be able to detect differences in socio-cultural aspects and external factors that could influence dietary decisions. Therefore, it could be a tool for other researchers with the same objective to evaluate larger and representative populations. The main strength of our study is the assessment of those consuming plant-based diets from different socio-cultural backgrounds. Our findings highlighted the relevance of developing campaigns promoting plant-based diets according to the socio-cultural background of each community. Additionally, we showed the necessity of supporting plant-based diets within an adequate food environment.

Understanding the reasons behind plant-based diet consumption in a specific environment is essential. Likewise, it is important to know the barriers to adopting it. Future research on the willingness of omnivores to embrace plant-based diets would shine light upon the difficulties in adopting plant-based dietary patterns. Additionally, former plant-based dieters could indicate the main obstacles that consumers face to continue these diets. This could lead to a better knowledge of the main reasons for adopting a plant-based diet, the barriers to starting, and the difficulties in maintaining such diets. This information could be used to implement measures to encourage a general transition to plant-based diets in a specific environment and their maintenance over time.

\section{Conclusions}

Altogether, our results provide further evidence about the influence of both the socio-cultural and the external factors in dietary decisions. Future studies assessing larger populations and from different socio-cultural and food environments should be carried out to corroborate our findings. Strategies to promote adherence to plant-based diets should be designed and implemented according to specific circumstances. Furthermore, promoting incentives, such as price reduction and increasing food availability in supermarkets, restaurants, work/study cafeterias, and governmental institutions, would encourage more widespread usage the of plant-based diets and also the consumption of more plant foods by meat consumers. 
Supplementary Materials: The following are available online at http:/www.mdpi.com/2071-1050/12/21/9093/s1, Table S1: Supplementary Table S1. Methodology followed in the study.

Author Contributions: Conceptualization, S.E.; methodology, U.F. and S.E.; validation, U.F. and S.E.; formal analysis, U.F. and S.E.; investigation, S.E.; writing-original draft preparation, U.F.; writing-review and editing, S.E. and W.J.C. All authors have read and agreed to the published version of the manuscript.

Funding: This research received no external funding.

Conflicts of Interest: The authors declare no conflict of interest.

\section{References}

1. Burlingame, B.; Dernini, S. Sustainable diets and biodiversity: Directions and solutions for policy, research and action. In Proceedings of the International Scientific Symposium Biodiversity and Sustainable Diets, United against Hunger, Rome, Italy, 3-5 November 2010; FAO: Rome, Italy, 2012.

2. Willett, W.; Rockstrom, J.; Loken, B.; Springmann, M.; Lang, T.; Vermeulen, S.; Garnett, T.; Tilman, D.; De Clerck, F.; Wood, A.; et al. Food in the Anthropocene: The EAT-Lancet Commission on healthy diets from sustainable food systems. Lancet 2019, 393, 447-492. [CrossRef]

3. Rose, D.; Heller, M.C.; Roberto, C.A. Position of the Society for Nutrition Education and Behavior: The Importance of Including Environmental Sustainability in Dietary Guidance. J. Nutr. Educ. Behav. 2019, 51, 3-15.e11. [CrossRef] [PubMed]

4. Tagtow, A.; Robien, K.; Bergquist, E.; Bruening, M.; Dierks, L.; Hartman, B.E.; Robinson-O'Brien, R.; Steinitz, T.; Tahsin, B.; Underwood, T.; et al. Academy of Nutrition and Dietetics: Standards of Professional Performance for Registered Dietitian Nutritionists (Competent, Proficient, and Expert) in Sustainable, Resilient, and Healthy Food and Water Systems. J. Acad. Nutr. Diet. 2014, 114, 475-488.e424. [CrossRef] [PubMed]

5. Nelson, M.E.; Hamm, M.W.; Hu, F.B.; Abrams, S.A.; Griffin, T.S. Alignment of Healthy Dietary Patterns and Environmental Sustainability: A Systematic Review. Adv. Nutr. 2016, 7, 1005-1025. [CrossRef] [PubMed]

6. Harvard University. What Is a Plant-Based Diet and Why Should You Try It? 2018. Available online: https://www. health.harvard.edu/blog/what-is-a-plant-based-diet-and-why-should-you-try-it-2018092614760 (accessed on 14 October 2018).

7. Baroni, L.; Cenci, L.; Tettamanti, M.; Berati, M. Evaluating the environmental impact of various dietary patterns combined with different food production systems. Eur. J. Clin. Nutr. 2007, 61, 279-286. [CrossRef]

8. Soret, S.; Mejia, A.; Batech, M.; Jaceldo-Siegl, K.; Harwatt, H.; Sabate, J. Climate change mitigation and health effects of varied dietary patterns in real-life settings throughout North America. Am. J. Clin. Nutr. 2014, 100, 490S-495S. [CrossRef]

9. Sabaté, J.; Harwatt, H.; Soret, S. Health outcomes and greenhouse gas emissions from varied dietary patternsis there a relationship? Ann. Nutr. Metab. 2015, 67, 547-548. [CrossRef]

10. Springmann, M.; Godfray, H.C.; Rayner, M.; Scarborough, P. Analysis and valuation of the health and climate change cobenefits of dietary change. Proc. Natl. Acad. Sci. USA 2016, 113, 4146-4151. [CrossRef]

11. Springmann, M.; Wiebe, K.; Mason-D'Croz, D.; Sulser, T.B.; Rayner, M.; Scarborough, P. Health and nutritional aspects of sustainable diet strategies and their association with environmental impacts: A global modelling analysis with country-level detail. Lancet Planet Health 2018, 2, e451-e461. [CrossRef]

12. Tilman, D.; Clark, M. Global diets link environmental sustainability and human health. Nature 2014, 515, 518-522. [CrossRef] [PubMed]

13. Whitmee, S.; Haines, A.; Beyrer, C.; Boltz, F.; Capon, A.G.; de Souza Dias, B.F.; Ezeh, A.; Frumkin, H.; Gong, P.; Head, P.; et al. Safeguarding human health in the Anthropocene epoch: Report of The Rockefeller Foundation-Lancet Commission on planetary health. Lancet 2015, 386, 1973-2028. [CrossRef]

14. Fresán, U.; Martinez-Gonzalez, M.A.; Sabate, J.; Bes-Rastrollo, M. Global sustainability (health, environment and monetary costs) of three dietary patterns: Results from a Spanish cohort (the SUN project). BMJ Open 2019, 9, e021541. [CrossRef]

15. Statista. Share of People Who Follow a Vegetarian Diet Worldwide as of 2016, by Region. Available online: https://www.statista.com/statistics/597408/vegetarian-diet-followers-worldwide-by-region/ (accessed on 14 July 2020). 
16. Janssen, M.; Busch, C.; Rodiger, M.; Hamm, U. Motives of consumers following a vegan diet and their attitudes towards animal agriculture. Appetite 2016, 105, 643-651. [CrossRef]

17. Rothgerber, H. A comparison of attitudes toward meat and animals among strict and semi-vegetarians. Appetite 2014, 72, 98-105. [CrossRef]

18. Ruby, M.B. Vegetarianism. A blossoming field of study. Appetite 2012, 58, 141-150. [CrossRef]

19. Fox, N.; Ward, K. Health, ethics and environment: A qualitative study of vegetarian motivations. Appetite 2008, 50, 422-429. [CrossRef]

20. Jabs, J.; Devine, C.M.; Sobal, J. Model of the Process of Adopting Vegetarian Diets: Health Vegetarians and Ethical Vegetarians. J. Nutr. Educ. 1998, 30, 196-202. [CrossRef]

21. Barr, S.I.; Chapman, G.E. Perceptions and practices of self-defined current vegetarian, former vegetarian, and nonvegetarian women. J. Am. Diet. Assoc. 2002, 102, 354-360. [CrossRef]

22. Rosenfeld, D.L. The psychology of vegetarianism: Recent advances and future directions. Appetite 2018, 131, 125-138. [CrossRef]

23. Corrin, T.; Papadopoulos, A. Understanding the attitudes and perceptions of vegetarian and plant-based diets to shape future health promotion programs. Appetite 2017, 109, 40-47. [CrossRef] [PubMed]

24. Hawkins, L.K.; Farrow, C.; Thomas, J.M. Do perceived norms of social media users' eating habits and preferences predict our own food consumption and BMI? Appetite 2020, 149, 104611. [CrossRef]

25. The Society for Nutrition and Behaviour. Vegetarian Trends. Available online: https://www.sneb.org/blog/ 2018/04/03/general/vegetarian-trends/ (accessed on 18 October 2020).

26. Stoll-Kleemann, S.; Schmidt, U.J.J.R.E.C. Reducing meat consumption in developed and transition countries to counter climate change and biodiversity loss: A review of influence factors. Reg. Environ. Chang. 2017, 17, 1261-1277. [CrossRef]

27. Waterlander, W.E.; Jiang, Y.; Nghiem, N.; Eyles, H.; Wilson, N.; Cleghorn, C.; Genç, M.; Swinburn, B.; Mhurchu, C.N.; Blakely, T. The effect of food price changes on consumer purchases: A randomised experiment. Lancet Public Health 2019, 4, e394-e405. [CrossRef]

28. Gittelsohn, J.; Rowan, M.; Gadhoke, P. Interventions in small food stores to change the food environment, improve diet, and reduce risk of chronic disease. Prev. Chronic Dis. 2012, 9, E59. [CrossRef]

29. United States Census Bureau. 2017. Available online: https://www.census.gov/quickfacts/ lomalindacitycalifornia (accessed on 15 October 2018).

30. Danmarks Statistik. Folketal (Summariske tal fra Folketællinger) efter Hovedlandsdele og tid. 2018. Available online: http://www.statbank.dk/statbank5a/SelectVarVal/saveselections.asp (accessed on 15 October 2018).

31. Beuttner, D. Blue Zones: The Science of Living Longer; National Geographic: Washington, DC, USA, 2016.

32. Fraser, G.E. Diet, Life Expectancy, and Chronic Disease: Studies of Seventh-Day Adventists and Other Vegetarians; Oxford University Press: Oxford, UK, 2003.

33. Dray, T. Which Foods Are on the 7th Day Adventist Diet? Available online: https://www.livestrong.com/ article/441583-what-foods-are-on-the-7th-day-adventist-diet/ (accessed on 14 October 2018).

34. European Union. Copenhagen European Green Capital 2014. 2013. Available online: http://ec.europa.eu/environment/europeangreencapital/wp-content/uploads/2013/02/CopenhagenPost-Assessment-Report-2014-EN.pdf (accessed on 14 October 2018).

35. Fountain, H.; Nagourney, A. California, at Forefront of Climate Fight, Won't Back Down to Trump. New York Times. 26 December 2016. Available online: https://www.nytimes.com/2016/12/26/us/californiaclimate-change-jerry-brown-donald-trump.html (accessed on 5 March 2019).

36. NBC Channel 4 Los Angeles. Los Angeles City Council Embraces “Meatless Mondays". 2012. Available online: https:/www.nbclosangeles.com/news/local/Los-Angeles-City-Council-Embraces-MeatlessMondays-Vegetarian-178244541.html (accessed on 5 March 2019).

37. Physicians Committee for Responsible Medicine. Landmark California Legislation Encourages Climate-Friendly, Plant-Based School Lunch Options. 2019. Available online: https://www.pcrm.org/news/ news-releases/landmark-california-legislation-encourages-climate-friendly-plant-based-school (accessed on 23 April 2019).

38. Haverstock, K.; Forgays, D.K. To eat or not to eat. A comparison of current and former animal product limiters. Appetite 2012, 58, 1030-1036. [CrossRef] 
39. Chuter, R. Finding Companionship on the Road Less Travelled: A Netnography of the Whole Food Plant-Based Aussies Facebook Group. 2018. Available online: https://ro.ecu.edu.au/theses_hons/1517/ (accessed on 14 October 2018).

40. World Health Organization. Diet, Nutrition, and the Prevention of Chronic Diseases; Report of a Joint WHO/FAO Expert Consultation; World Health Organisation: Geneva, Switzerland, 2003; Available online: https://apps.who.int/iris/bitstream/handle/10665/42665/WHO_TRS_916.pdf;jsessionid= 3426EEFACB3E2F9A2CCE6328DD98D183? sequence=1 (accessed on 14 October 2018).

Publisher's Note: MDPI stays neutral with regard to jurisdictional claims in published maps and institutional affiliations.

(C) 2020 by the authors. Licensee MDPI, Basel, Switzerland. This article is an open access article distributed under the terms and conditions of the Creative Commons Attribution (CC BY) license (http://creativecommons.org/licenses/by/4.0/). 